\title{
Uleksitin Amonyum Sülfat Çözeltilerindeki Çözünürlüğüne Dehidrasyon İşleminin Etkisi
}

\author{
*11Nizamettin DEMİRKIRAN(0000-0001-9021-2477), ${ }^{2}$ Mehmet Kayra TANAYDIN(0000-0003-1696-0754), ${ }^{1}$ G.Deniz \\ TURHAN ÖZDEMIR(0000-0003-4749-1989) \\ ${ }^{1}$ İnönü Üniversitesi Mühendislik Fakültesi Kimya Mühendisliği Bölümü, 44280, Malatya \\ ${ }^{2}$ Munzur Üniversitesi Mühendislik Fakültesi Kimya Mühendisliği Bölümü, 62000, Tunceli \\ nizamettin.demirkiran@inonu.edu.tr \\ Geliş Tarihi: 21.12.2017 Kabul Tarihi: 31.05.2018
}

Öz

Uleksit ticari olarak önemli bor minerallerinden birisi olup Türkiye’de bol miktarda bulunmaktadır. Uleksit genellikle diğer boratlarla birlikte bulunur ve bor bileşikleri üretiminde ham madde olarak kullanılabilir. Önemli miktarda hidratasyon suyu içeren uleksit, dehidrasyon işlemine maruz bırakıldığı zaman uygulanan sıcaklığa bağlı olarak bu suyun bir kısmını kaybeder. Dehidrasyon işlemi sonucunda kimyasal olarak daha aktif olan gözenekli bir katı elde edilir. Oluşan gözenekli yapı katı ile akışkan arasındaki reaksiyonun daha kolaylıkla meydana gelmesine olanak sağlar ve çözünme hızı artar.

$\mathrm{Bu}$ çalışmada, kalsine edilmiş uleksitin amonyum sülfat çözeltilerindeki çözünme kinetiği incelenmiştir. Deneylerde uleksitin çözünmesi üzerine dehidrasyon sıcaklığı, çözelti derişimi, reaksiyon sıcaklığı, katı/sıvı oranı ve karıştırma hızının etkileri araştırılmıştır. Çözelti derişimi ve sıcaklığın artması, katı/sıvı oranının ise azalmasıyla reaksiyon hızının arttığı gözlenmiştir. En yüksek çözünme hızı $150^{\circ} \mathrm{C}$ 'de kalsine edilmiş örneklerden elde edilmiştir. Çözünme kinetiğinin yalancı birinci mertebe kinetik modele uyduğu belirlenmiştir. Çözünme prosesi için aktivasyon enerjisinin değeri $42 \mathrm{~kJ} / \mathrm{mol}$ olarak hesaplanmıştır.

Anahtar Kelimeler: Uleksit, Kalsinasyon, Çözünme kinetiği.

\section{Effect of Dehydration Treatment on Dissolution of Ulexite in Ammonium Sulfate Solutions}

\author{
* ${ }^{1}$ Nizamettin DEMIRKIRAN, ${ }^{2}$ Mehmet Kayra TANAYDIN, ${ }^{1}$ G.Deniz TURHAN ÖZDEMIR \\ ${ }^{1}$ İnönü University, Faculty of Engineering, Department of Chemical Engineering, 44280, Malatya \\ ${ }^{2}$ Munzur University, Faculty of Engineering, Department of Chemical Engineering, 62000, Tunceli \\ nizamettin.demirkiran@inonu.edu.tr
}

\begin{abstract}
Ulexite is commercially one of important boron minerals, and it is found abundantly in Turkey. Ulexite is generally available together with other borates, and it can be used as a raw material in the production of boron compounds. It includes a significant amount of hydration water. When ulexite is subjected a dehydration process, it loses some part of hydrate water depending upon applied temperature. A porous solid is obtained in consequence of dehydration treatment, and the solid material becomes more chemically active. The resulting porous structure allows occurring more readily the reaction between solid and fluid, and the dissolution rate increases.
\end{abstract}

In this study, the dissolution kinetics of calcined ulexite in ammonium sulfate solutions was examined. In the experiments, the effects of the dehydration temperature, solution concentration, reaction temperature, solid-to-liquid ratio, and stirring speed on

*Sorumlu Yazar: ${ }^{1}$ İnönü Üniversitesi Mühendislik Fakültesi Kimya Mühendisliği Bölümü, 44280, Malatya, . nizamettin.demirkiran@inonu.edu.tr, Tel: 0422-3774760 
dissolution of ulexite were investigated. It was observed that the reaction rate increased with increasing solution concentration and reaction temperature, and with decreasing solid-to-liquid ratio. The highest dissolution rate was obtained with the sample calcined at $150^{\circ} \mathrm{C}$. It was determined that the dissolution kinetics fit to the first order pseudo-homogeneous kinetic model. The activation energy of the dissolution process was calculated to be $42 \mathrm{~kJ} / \mathrm{mol}$.

Keywords: Ulexite, Calcination, Dissolution kinetics

\section{GİRIŞ}

Teknolojinin hızlı gelişmesine bağlı olarak başta borik asit olmak üzere çeşitli bileşikleri halinde geniş bir kullanım alanına sahip olan bor, doğada genellikle alkali ve toprak alkali metal boratları halinde bulunur. Bor mineralleri içerdikleri $\mathrm{B}_{2} \mathrm{O}_{3}$ yüzdesine göre değer kazanırlar ve yapılarında genellikle kristal suyu barındırırlar. Endüstriyel ve ekonomik sebeplerden dolayı yapılarında kristal suyu bulunduran bor minerallerine bir 1sıl işlem uygulandığı zaman sicaklığa ve zamana bağlı olarak bu suyun bir kısmını veya tamamını verirler. Bu işlem dehidrasyon veya kalsinasyon olarak bilinir. Kalsinasyon işleminin uygulanmasıyla mineralin içermiş olduğu su miktarı azaltılabilir veya tamamen uzaklaştırılabilir. Bunun sonucunda konsantre cevher elde edilerek $\mathrm{B}_{2} \mathrm{O}_{3}$ tenörü yükseltilmiş ve cevherin fiyatının artması sağlanmış olur. Dehidrasyon prosesinin uygulanması sırasında oluşan su buharının yapıyı terk etmesiyle çok sayıda mikro çatlaklar meydana gelir ve gözenekli bir katı elde edilmiş olur. Gözenekli bir yapının oluşması neticesinde mineral kimyasal olarak daha aktif hale gelir. Kalsine edilmiş mineral liç işlemine tabi tutulduğu zaman çözücü ile gözenekli katı arasındaki reaksiyon kolaylaşır ve borik asidin katı fazdan çözelti ortamına ekstraksiyon hızı arttırılmış olur [1-4].

Kimyasal formülü $\mathrm{Na}_{2} \mathrm{O} \cdot 2 \mathrm{CaO} \cdot 5 \mathrm{~B}_{2} \mathrm{O}_{3} \cdot 16 \mathrm{H}_{2} \mathrm{O}$ olan uleksit ekonomik değere sahip önemli bor minerallerinden birisi olup genellikle diğer boratlarla birlikte bulunur ve borik asit üretiminde kullanılabilir. Uleksitin dehidrasyonu farklı araştırmacılar tarafından incelenmiştir. Deney şartlarına bağlı olarak uleksitin dehidrasyonunun 60-100 ${ }^{\circ} \mathrm{C}$ arasındaki sıcaklıklarda başladığı ve 190-240 ${ }^{\circ} \mathrm{C}$ sıcaklıklara kadar dehidrasyonun oldukça hızlı olduğu, bu sıcaklıklardan daha yüksek sıcaklıklarda 500-530 ${ }^{\circ} \mathrm{C}$ 'ye kadar reaksiyonun yavaş bir şekilde ilerlediği ve daha yüksek sıcaklıklarda ise hemen hemen hiç ağırlık kaybının olmadığı araştırmacılar tarafından ifade edilmiştir. Termal dekompozisyon sirasında dehidrasyon ve dehidroksilasyon olmak üzere iki tür reaksiyonun gerçekleştiği, uygulanan sıcaklığa ve zamana bağlı olarak cevherin yapısında bazı değişikliklerin de meydana geldiği belirtilmiştir. Dehidrasyonla yapıya bağlı bulunan kristalizasyon suyu uzaklaşırken dehidroksilasyonla hidroksil birleşmesi sonucunda oluşan su molekülleri uzaklaşmaktadır. 240 ${ }^{\circ} \mathrm{C}$ 'nin altındaki sıcaklıklarda yapılan dehidrasyon işlemi

$$
\% \text { Kütle kaybı }=\left(\frac{m_{0}-m}{m_{0}}\right) \cdot 100
$$

sonucunda daha gözenekli bir katı elde edilirken bu sıcaklıktan sonra amorflaşmanın hızlanmasıyla sert ve tamamen amorf yapıda bir katı oluşmaktadır [4-8].

Dehidrasyon işlemine tabi tutulmuş veya kalsine edilmiş uleksitin sülfürik asit [9], amonyum klorür [10], etilen diamin tetra asetik asit [11], okzalik asit [12], amonyum karbonat [13], amonyum nitrat [14] ve amonyum asetatın [15] sulu çözeltilerinde çözünme kinetiği incelenmiştir. Bu çalışmalarda, farklı sıcaklıklarda kalsine edilmiş uleksitin çözünürlükleri belirlenmiş ve genellikle $140-160{ }^{\circ} \mathrm{C}$ arasındaki sıcaklıklarda kalsine edilmiş katılardan en yüksek çözünürlük değerlerinin elde edildiği tespit edilmiştir. Daha yüksek kalsinasyon sıcaklıklarında hazırlanan uleksit örnekleri ile yapılan deneylerde ise çözünürlüğün azaldığı belirlenmiş ve bu azalma sinterlenme olayına bağlanmıştır.

Önceki çalışmada kalsinasyon işlemine tabi tutulmamış uleksit örneklerinin amonyum sülfat çözeltilerindeki çözünme kinetiği incelenmiştir [16]. Bu çalışmada, farklı sıcaklıklarda kalsine edilmiş uleksit örneklerinin amonyum sülfat çözeltilerindeki çözünme kinetiği araştırılmıştır. Kalsinasyon sıcaklığı, çözelti derişimi, reaksiyon sıcaklığı, katı/sıvı oranı ve karıştırma hızının kalsine uleksitin çözünmesi üzerine olan etkileri belirlenmiştir.

\section{MATERYAL VE METOT}

Çalışmada kullanılan uleksit minerali Eskişehir, Kırka'dan temin edilmiştir. Mineral kırılıp öğütüldükten sonra farklı parçacık boyutlarına sahip örnekler elde etmek için elenmiştir. Mineralin kimyasal analizi sonucunda \% 42.08 $\mathrm{B}_{2} \mathrm{O}_{3}, \% 13.98 \mathrm{CaO}$, \% $7.95 \mathrm{Na}_{2} \mathrm{O}$, \% $35.82 \mathrm{H}_{2} \mathrm{O}$ ve \% 0.17 çözünmeyen kısımdan ibaret olduğu tespit edilmiştir. Uleksit mineralinin XRD analiz sonucu Şekil 1'de ve SEM görüntüsü ise Şekil 2'de gösterilmiştir.

Uleksitin izotermal dehidrasyonu $-0.84+0.42 \mathrm{~mm}$ ortalama parçacık boyutuna sahip örnekler kullanılarak $100-250{ }^{\circ} \mathrm{C}$ sıcaklık aralığında bir etüvde yapılmıştır. Mineralden $1 \mathrm{~g}$ alınarak porselen krozelere konulmuş ve $180 \mathrm{dk}$ süresince farklı sıcaklıklarda kalsinasyon işlemi gerçekleştirilmiştir. Dehidrasyon işleminden sonra krozeler etüvden çıkarılıp bir desikatöre konulmuş ve sabit tartıma getirilmiştir. Kalsine edilmiş örneğin kütlesinden başlangıçtaki kütle çıkarılarak mineralden uzaklaşan su miktarı Eşitlik 1'deki denklemle hesaplanmıştır.

Bu bağıntıdaki $m_{o}$ dehidrasyon işleminden önce uleksitin kütlesini $(g), m$ ise dehidrasyon işleminden sonra kalsine uleksitin kütlesini $(g)$ göstermektedir. Kalsine edilmiş örneklerin $\mathrm{B}_{2} \mathrm{O}_{3}$ içerikleri uzaklaşan su kütlesi dikkate alınarak teorik olarak hesaplanmıştır. 


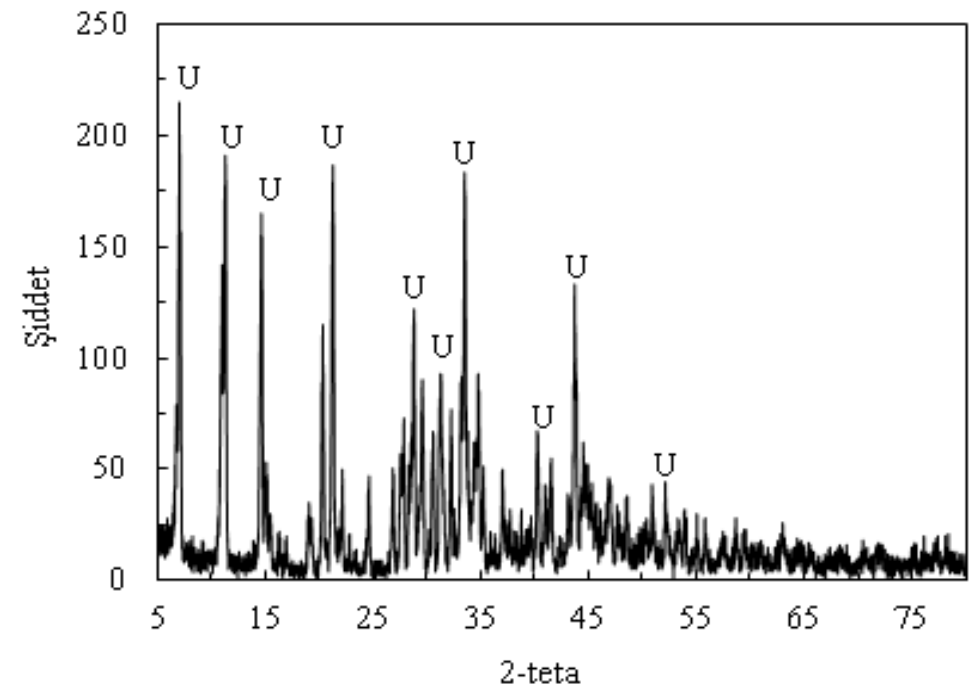

Şekil 1. Kalsine edilmemiş uleksit örneğine ait XRD difraktogramı.

Kalsine uleksitin çözünürlüğünün incelendiği deneyler 500 $\mathrm{mL}$ hacimli ceketli bir cam reaksiyon kabında yapılmıştır. Çözünme reaksiyonları sırasında sıcaklığı sabit tutmak için sirkülatörlü su banyosundan yararlanılmış ve reaktör içeriği bir mekanik karıştırıcı ile karıştırılmıştır. Derişimi bilinen $200 \mathrm{~mL}$ amonyum sülfat çözeltisi cam reaktöre konulduktan sonra bu çözelti reaksiyon sıcaklığına ulaşıncaya kadar isıtılmıştır. Çalışılacak sıcaklığa ulaşıldıktan sonra belirli miktarda kalsine uleksit örneği reaktöre ilave edilmiş ve reaktör içeriği karıștırılmıştır. Farklı zamanlarda reaktörden çözelti örnekleri alınmak suretiyle kalsine uleksitten çözünerek çözelti ortamına geçmiş olan $\mathrm{B}_{2} \mathrm{O}_{3}$ miktarı belirlenmiştir. $\mathrm{B}_{2} \mathrm{O}_{3}$ tayini analizi yapılacak çözeltiye mannitol ilave edildikten sonra sodyum hidroksit çözeltisi kullanılarak titrimetrik yöntemle yapılmıştır [17]. Kalsine uleksitin çözünme kesri Eşitlik 2 kullanılarak hesaplanmıştır.

$$
X_{B_{2} O_{3}}=\frac{\text { Çözeltideki } B_{2} O_{3} \text { miktarl }}{\text { Kalsine edilmiş uleksitteki } B_{2} O_{3} \text { miktarı }}
$$

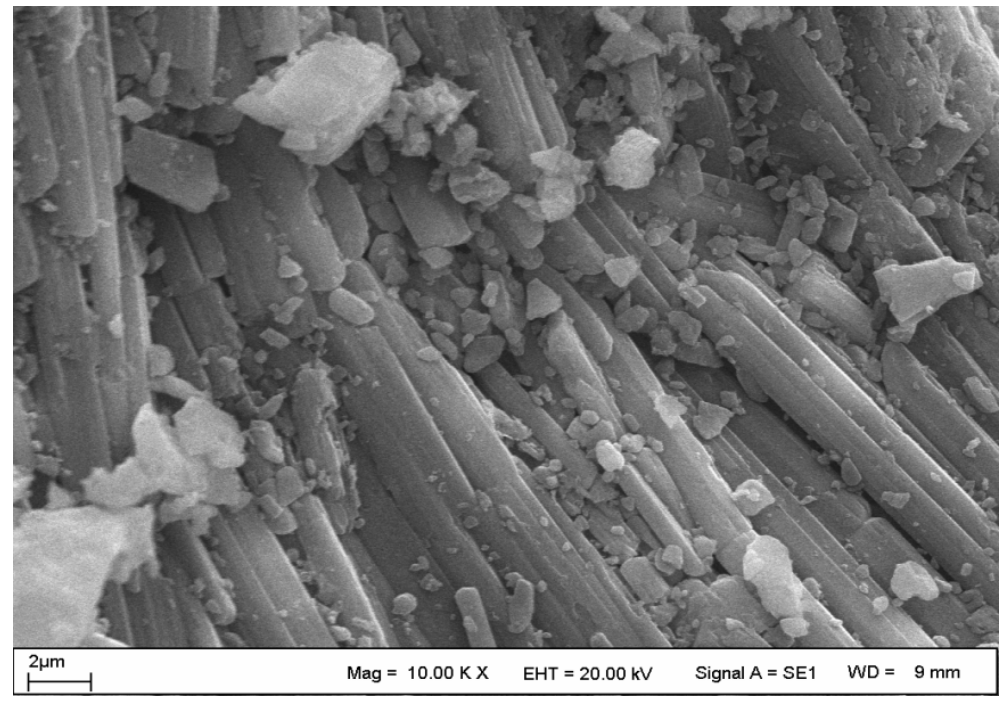

Şekil 2. Kalsine edilmemiş uleksit örneğine ait SEM görüntüsü. 


\section{BULGULAR ve TARTIŞMA}

Uleksitin dehidrasyon reaksiyonu Eşitlik 3’teki gibi yazılabilir.

$$
\mathrm{Na}_{2} \mathrm{O} .2 \mathrm{CaO} .5 \mathrm{~B}_{2} \mathrm{O}_{3} \cdot 16 \mathrm{H}_{2} \mathrm{O}(\mathrm{k}) \rightarrow \mathrm{Na}_{2} \mathrm{O} \cdot 2 \mathrm{CaO} .5 \mathrm{~B}_{2} \mathrm{O}_{3} \cdot \mathrm{nH}_{2} \mathrm{O}(\mathrm{k})+(16-\mathrm{n}) \mathrm{H}_{2} \mathrm{O}(\mathrm{g})
$$

Burada n dehidrasyon işleminden sonra katıda kalan suyun mol sayısıdır. Dehidrasyon sıcaklığındaki artışla birlikte mineralden uzaklaşan su miktarında da bir artma meydan gelir. Katıdaki su miktarı azaldıkça kalsine edilmiş olan mineral örneğinin birim kütlesindeki $\mathrm{B}_{2} \mathrm{O}_{3}$ miktarında ise bir artma söz konusu olur. $180 \mathrm{dk}$ kalsinasyon süresinden sonra 100 ve $250{ }^{\circ} \mathrm{C}$ 'lerde kalsine edilmiş uleksitin su içeriğinin sırasıyla $\% 7.52$ ve $\% 30.42$ azaldığ

$\mathrm{Na}_{2} \mathrm{O} \cdot 2 \mathrm{CaO} \cdot 5 \mathrm{~B}_{2} \mathrm{O}_{3} \cdot \mathrm{nH}_{2} \mathrm{O}(\mathrm{k})+3\left(\mathrm{NH}_{4}\right)_{2} \mathrm{SO}_{4}(\mathrm{aq})+(12-\mathrm{n}) \mathrm{H}_{2} \mathrm{O}(\mathrm{s}) \rightarrow$

$\mathrm{Na}_{2} \mathrm{SO}_{4}(\mathrm{aq})+2 \mathrm{CaSO}_{4}(\mathrm{k})+6 \mathrm{NH}_{3}(\mathrm{aq})+10 \mathrm{H}_{3} \mathrm{BO}_{3}(\mathrm{aq})$

\section{1. Çözünme Üzerine Kalsinasyon Sıcaklığının Etkisi}

Uleksit mineralinin amonyum sülfat çözeltilerinde çözünmesi üzerine dehidrasyon işleminin etkisini görmek için 100, 120, 140, 150, 160, 180, 200 ve $250{ }^{\circ} \mathrm{C}$ sıcaklıklarda kalsine edilmiş uleksit örnekleri kullanılarak deneyler yapılmıştır. Bu deneylerde çözelti derişimi, karıştırma hızı, katı/sıvı oranı ve reaksiyon sıcaklığı sirasiyla $1 \mathrm{~mol} / \mathrm{L}, 400 \mathrm{rpm}, 2 / 200 \mathrm{~g} / \mathrm{mL}$ ve $30{ }^{\circ} \mathrm{C}$ değerlerinde alınmıştır. Şekil 3’te $20 \mathrm{dk}$ deney süresi sonunda elde edilen çözünme değerleri verilmiştir. 150

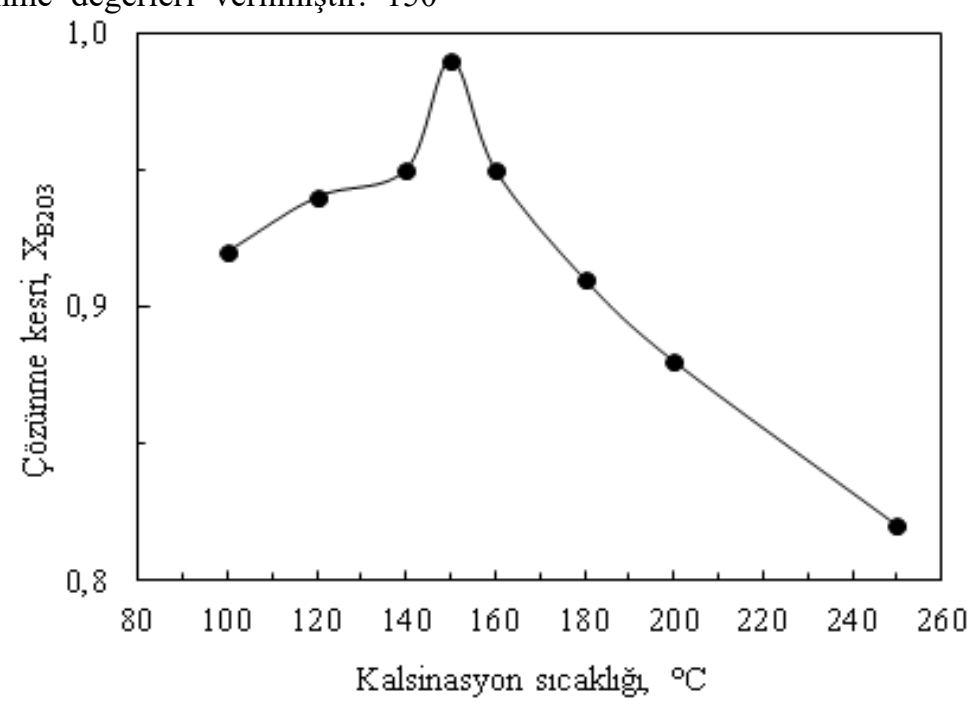

Şekil 3. Kalsine edilmiş uleksitin çözünmesine kalsinasyon sıcaklığının etkisi.

Yukarıda da ifade edildiği gibi dehidrasyon ișlemi ile uygulanan sıcaklığa bağlı olarak katıdaki kristal suyunun bir kısmı uzaklaşır ve gözenekli bir yapı oluşur. Şekil 4’te $150{ }^{\circ} \mathrm{C}^{\prime}$ de kalsine edilmiş uleksite ait SEM görüntüsü verilmiştir. Şekil 2'de verilmiş olan kalsine edilmemiş uleksit örneğine ait SEM görüntüsü ile Şekil 4'te verilmiş olan kalsine edilmiş örneğe ait SEM görüntüsü mukayese belirlenmiştir. $\mathrm{Bu}$ kütle kaybı sebebiyle 100 ve 250 ${ }^{\circ} \mathrm{C}$ 'lerde kalsine edilmiş örneklerin birim kütlesinde $\mathrm{B}_{2} \mathrm{O}_{3}$ içeriği ise sırasıyla $\% 46.46$ ve $\% 61.75$ olarak hesaplanmıştır.

Amonyum sülfat çözeltisine kalsine uleksit ilave edildiği zaman meydana gelebilecek toplam çözünme reaksiyonu Eşitlik (4)'deki gibi yazılabilir.
${ }^{\circ} C^{\prime}$ ye kadar olan sicaklıklarda kalsine edilmiş örneklerle yapılan deneylerde uleksitin çözünme kesrinin arttığı, en yüksek çözünme değerlerine $150{ }^{\circ} \mathrm{C}$ 'de kalsine edilmiş örneklerde ulaşıldığı ve bu sıcaklıktan daha yüksek sıcaklıklarda kalsine edilmiş örneklerin ise çözünürlüğünün azaldığı gözlenmiştir. $150{ }^{\circ} \mathrm{C}$ 'de kalsine edilmiş uleksitteki $\mathrm{B}_{2} \mathrm{O}_{3}$ 'ün \%99'unun çözünerek çözeltiye geçtiği tespit edilmiştir. Aynı deney şartları ve deney süresi için kalsine edilmemiş örnekle yapılan deneyde ise \%35'lik bir çözünme değeri elde edilmiştir.

edildiği zaman, dehidrasyon işlemine tabi tutulan örnekte çatlaklar gözlenmektedir. Kalsine edilmiş katı çözünme işlemine tabi tutulduğu zaman çözücü reaktif bu çatlak veya boşluklardan katı iç kısımlarına doğru daha kolay bir şekilde nüfuz edebilir ve çözünme hızında bir artış söz konusu olabilir. 


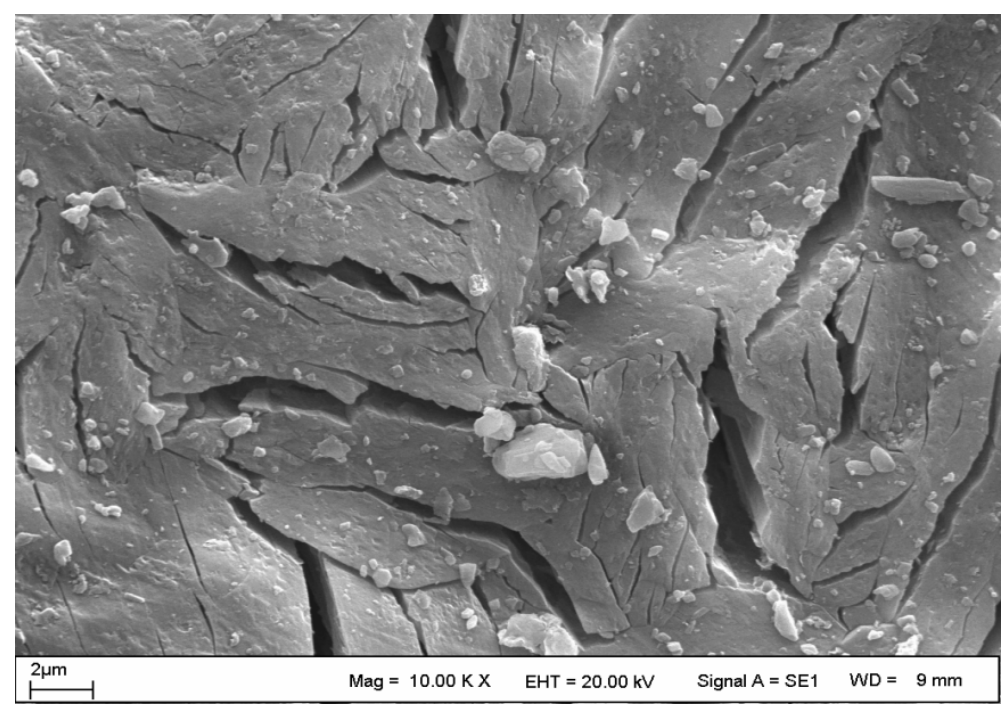

Şekil 4. $150{ }^{\circ} \mathrm{C}$ 'de kalsine edilmiş uleksit örneğine ait SEM görüntüsü.

Dehidrasyon sıcaklığının daha fazla arttırılması sinterlenmeye sebep olabilir ve bunun sonucunda oluşan çatlak veya boşluklar kısmen tıkanabilir. Bu durum katıda gözeneklerin azalmasına sebep olacağından akışkan çözücünün katı içine doğru difüzlenmesi zorlaşabilir ve neticede kalsine edilmiş katının çözünme hızı azalabilir. $200{ }^{\circ} C^{\prime}$ 'de kalsine edilmiş örneğe ait SEM görüntüsü Şekil 5'te gösterilmiştir. Şekil 5'te sinterleşmeden dolayı gözeneklerin kısmen tıkanmış olduğu gözlenmektedir.

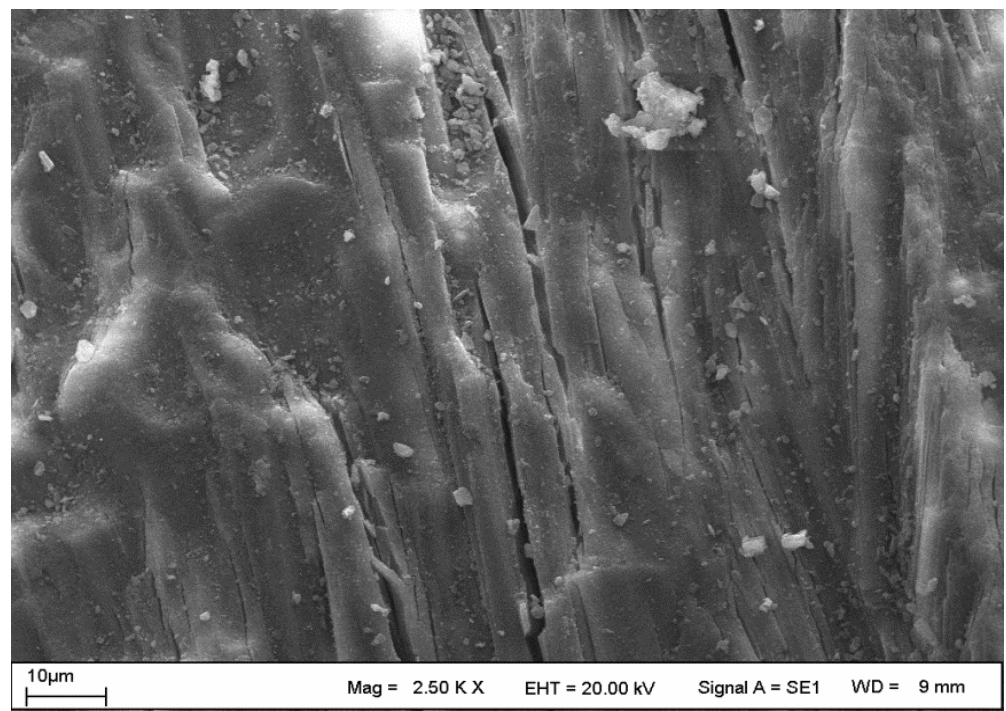

Şekil 5. $200{ }^{\circ} \mathrm{C}$ 'de kalsine edilmiş uleksit örneğine ait SEM görüntüsü.

Elde edilen bulgulara göre dehidrasyon ișleminin uleksit mineralinin çözünmesi üzerinde önemli bir etkisinin olduğu söylenebilir.

Daha yüksek çözünme değerleri $150{ }^{\circ} \mathrm{C}$ 'de kalsine edilmiş örnekten elde edildiğinden diğer parametrelerin çözünme hızı üzerindeki etkisi incelenirken bu sıcaklıkta kalsine edilmiş uleksit örnekleri kullanılmıştır.

\section{2. Çözünme Üzerine Çözelti Derişiminin Etkisi}

Kalsine uleksitin amonyum sülfat çözeltilerinde çözünme hızı üzerine çözelti derişiminin etkisi $0.10,0.25,0.50$ ve $1.00 \mathrm{~mol} / \mathrm{L}$ derişim değerlerinde incelenmiştir. Deneylerde katı/sıvı oranı 2/200 g/mL, karıştırma hızı 400 rpm ve reaksiyon sıcaklığı $30{ }^{\circ} \mathrm{C}$ olarak alınmıştır. Şekil 6 bu deneylere ait sonuçları göstermektedir. $\mathrm{Bu}$ şekilden 
görüleceği gibi çözelti derişimi arttıkça kalsine edilmiş uleksitin çözünme kesri de artmaktadır.

Amonyum sülfat sulu ortamda iyonlaştığı zaman açı̆̆a çıkan amonyum iyonları $\left(\mathrm{NH}_{4}{ }^{+}\right)$hidroliz reaksiyonuyla hidronyum $\left(\mathrm{H}_{3} \mathrm{O}^{+}\right)$iyonlarını oluşturur. Bazik karaktere sahip olan uleksit mineralinin çözünmesinde esas olarak hidronyum iyonları rol alır. Amonyum sülfat derișimi arttıkça oluşan hidronyum derişimi de artacağından kalsine uleksitin çözünme hızı artmış olur.

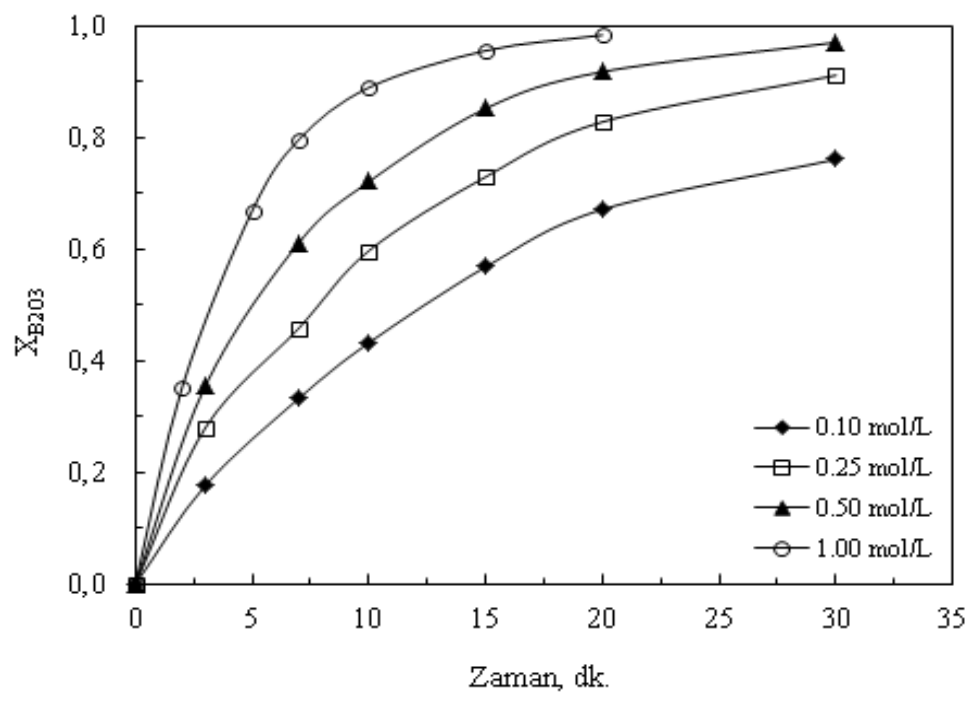

Şekil 6. Kalsine edilmiş uleksitin çözünmesine çözelti derişiminin etkisi.

\section{3. Çözünme Üzerine Karıştırma Hızının Etkisi}

Karıştırma hızının kalsine uleksitin çözünmesi üzerine olan etkisi 200-500 rpm aralığında farklı karıştırma hızlarında araştırılmıştır. Bu deneyler yapılırken diğer deneysel parametreler olan çözelti derişimi, katı/sıvı oranı ve reaksiyon sicaklığı sirasıyla $1 \mathrm{~mol} / \mathrm{L}, 2 / 200 \mathrm{~g} / \mathrm{mL}$ ve 30 ${ }^{\circ} \mathrm{C}$ değerlerinde alınmıştır. Karıştırma hızının etkisinin incelendiği deneylerden elde edilen veriler Şekil 7'de grafiksel olarak gösterilmiştir. Şekil 7'den görüldüğü gibi karıştırma hızının artması ile çözünme hızında bir miktar artış olmuştur. Karıştırma hızının artmasıyla katı etrafındaki durgun sıvı film tabakasının kalınlığı azaltılmış olur. Böylece katı yüzeyine doğru dış difüzyon direnci azalacağından çözünme hızında bir artış söz konusu olacaktır.

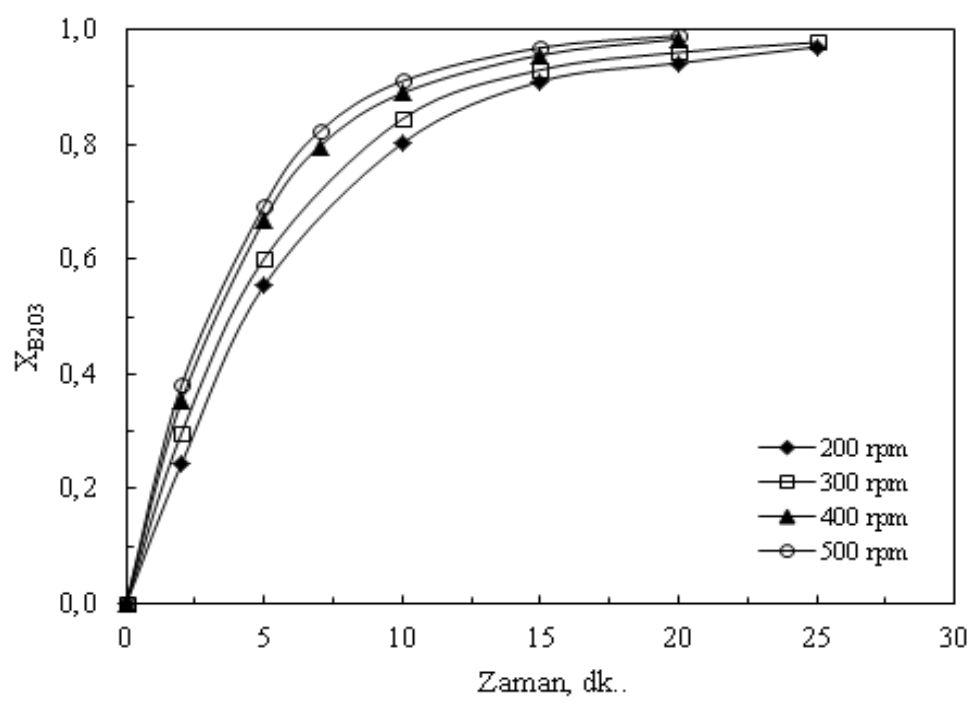

Şekil 7. Kalsine edilmiş uleksitin çözünmesine karıştırma hızının etkisi. 


\section{4. Çözünme Üzerine Katı/Sıvı Oranının Etkisi}

Katı/sıvı oranının çözünme hızı üzerine olan etkisini incelemek için $1 / 200,2 / 200$ ve $4 / 200 \mathrm{~g} / \mathrm{mL}$ katı/sıv1 oranlarında deneyler yapılmıştır. Çözelti derişimi $1 \mathrm{~mol} / \mathrm{L}$, karıştırma hızı $400 \mathrm{rpm}$ ve reaksiyon sıcaklığı $30{ }^{\circ} \mathrm{C}$ değerlerinde alınmıştır. $\mathrm{Bu}$ deneylere ait sonuçların verildiği Şekil 8'e göre katı/sıvı oranının azalmasıyla çözünme hızında artış olmaktadır. Katı/sıvı oranının azalmasıyla çözücünün birim hacmi başına düșen katı miktarında azalma olacağından çözünme hızında artış olmaktadır.

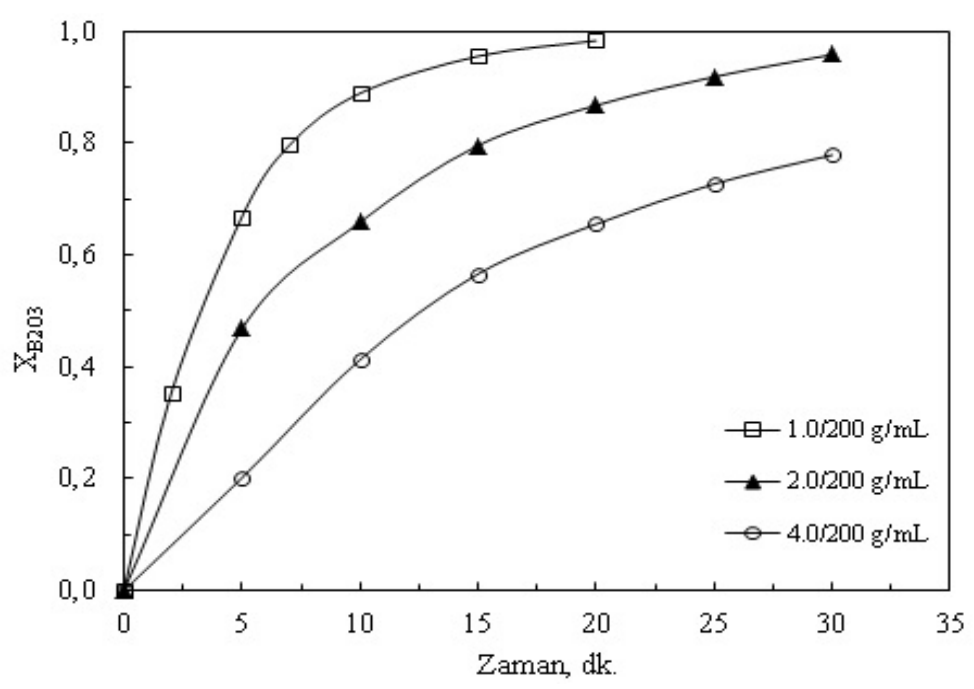

Şekil 8. Kalsine edilmiş uleksitin çözünmesine katı/sıvı oranının etkisi.

\section{5. Çözünme Üzerine Sıcaklığın Etkisi}

Reaksiyon sıcaklığının kalsine uleksitin çözünmesi üzerine olan etkisi $25-45{ }^{\circ} \mathrm{C}$ aralığında farklı sıcaklıklarda incelenmiştir. Bu deneyler yapılırken çözelti derişimi 1 mol/L, karıştırma hızı $400 \mathrm{rpm}$ ve katı/sıvı oranı 2/200 $\mathrm{g} / \mathrm{mL}$ değerlerinde alınmıştır. Şekil 9'da verilen deney sonuçlarına göre sıcaklı̆̆ın artmasıyla kalsine uleksitin çözünme kesri değerinde artış olmaktadır. Reaksiyon sıcaklığının artmasıyla moleküller daha hızlı hareket ederek birbirleriyle daha sık çarpışırlar. Bunun sonucunda moleküllerin reaksiyona girme olasılıkları artmış olur. Ayrıca reaksiyon hız sabitinin sıcaklığa üstel olarak bağlı olması sebebiyle sıcaklıktaki küçük artı̧̧lar dahi reaksiyon hızında önemli bir artmaya sebep olabilir.

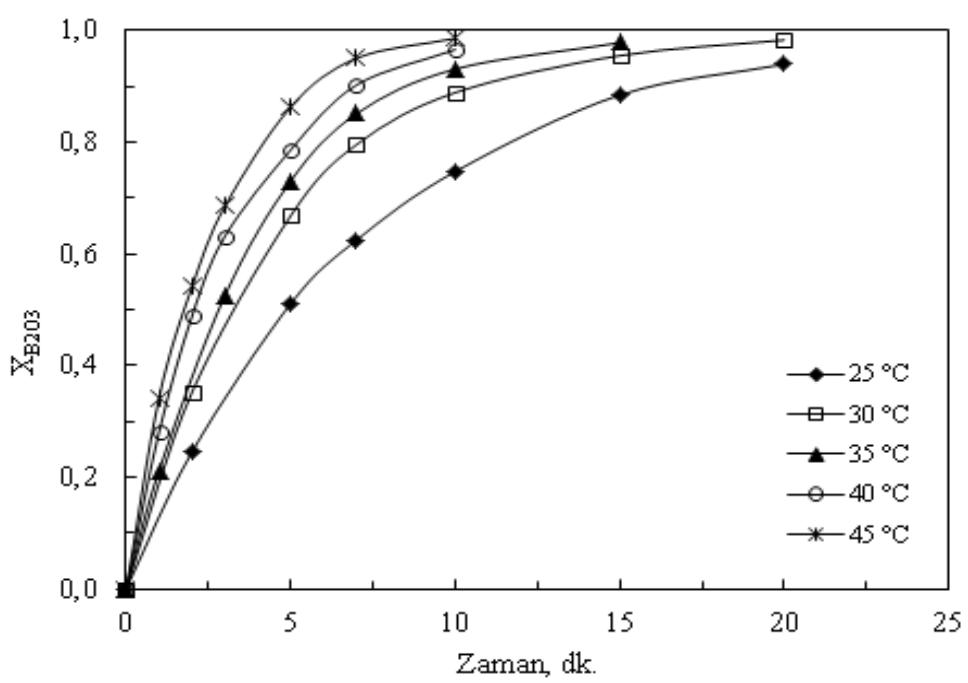

Şekil 9. Kalsine edilmiş uleksitin çözünmesine reaksiyon sıcaklığının etkisi.

Amonyum sülfat çözeltilerinde uleksitin çözünmesi üzerine dehidrasyon işleminin etkisini daha iyi görebilmek için Çizelge 1'de hem kalsine edilmemiş [16] hem de kalsine edilmiş uleksit örnekleri ile yapılmış olan 
deneylerin sonuçları topluca verilmiştir. Çizelge 1'den açıkça görüleceği gibi her bir deneysel parametrenin aynı değeri için kalsine uleksit örnekleri kullanılarak yapılan deneylerde daha kısa sürelerde yüksek dönüşüm değerlerine ulaşılmaktadır.

Tablo 1. Kalsine edilmemiş ve kalsine edilmiş uleksit ile yapılan deneylerden elde edilen sonuçlar.

\begin{tabular}{l|c|cc|cc}
\hline \multirow{2}{*}{\multicolumn{2}{c}{ Parametre ve değerler }} & \multicolumn{2}{c|}{ Kalsine edilmemiş uleksit } & \multicolumn{2}{c}{ Kalsine edilmiş uleksit } \\
\cline { 3 - 6 } \multicolumn{2}{l}{} & $\begin{array}{c}\text { Reaksiyon } \\
\text { süresi, dk. }\end{array}$ & $\begin{array}{c}\% \\
\text { Çözünme }\end{array}$ & $\begin{array}{c}\text { Reaksiyon } \\
\text { süresi, dk. }\end{array}$ & $\begin{array}{c}\% \\
\text { Çözünme }\end{array}$ \\
\hline \multirow{3}{*}{ Derişim, mol/L } & 0.10 & 90 & 54 & 30 & 76 \\
& 0.25 & 90 & 65 & 30 & 91 \\
& 0.50 & 90 & 77 & 30 & 97 \\
Kat1/sıvı oranı, & 1.00 & 90 & 90 & 20 & 99 \\
g/mL & $1 / 200$ & 90 & 90 & 20 & 99 \\
& $2 / 200$ & 90 & 74 & 30 & 96 \\
Karıştırma hızı, & $4 / 200$ & 90 & 53 & 30 & 78 \\
rpm & 200 & 90 & 81 & 25 & 96 \\
& 300 & 90 & 86 & 25 & 98 \\
& 400 & 90 & 90 & 20 & 99 \\
& 500 & 90 & 94 & 20 & 99 \\
\hline \multirow{3}{*}{ Sicaklık, ${ }^{\circ} \mathrm{C}$} & 25 & 90 & 82 & 20 & 94 \\
& 30 & 90 & 90 & 20 & 99 \\
& 35 & 45 & 92 & 15 & 98 \\
\hline
\end{tabular}

\section{6. Çözünme Kinetiği}

Kalsine uleksit ile amonyum sülfat çözeltisi arasındaki reaksiyon katı sivı heterojen bir reaksiyondur. $\mathrm{Bu}$ tip reaksiyonların kinetik analizi genellikle katalitik olmayan katı akışkan heterojen reaksiyon modelleri kullanılarak yapılmaktadır. $\mathrm{Bu}$ modeller arasında büzülen çekirdek

$$
\begin{aligned}
& x=k_{l} \cdot t \quad \text { (akışkan filminden difüzyon) } \\
& 1-(1-x)^{\frac{1}{3}}=k_{r} \cdot t \quad \text { (kimyasal reaksiyon) } \\
& 1-3(1-x)^{\frac{2}{3}}+2(1-x)=k_{d} \cdot t \text { (ürün veya kül tabakasından difüzyon) }
\end{aligned}
$$

modeli liç veya çözünme reaksiyonlarının kinetik analizi için sıklıkla kullanılmaktadır. Söz konusu modele göre bir liç reaksiyonun hızı akışkan filminden difüzyon, kimyasal reaksiyon veya ürün tabakasından difüzyon basamaklarından biri veya birkaçı tarafından kontrol edilebilir. Bu modeller için integre edilmiş hız ifadeleri Eşitlik 5-7'deki gibi yazılabilir [18, 19].
Yukarıdaki eşitliklerde, $x$ dönüşüm kesrini, $k_{l}$ akışkan filminden difüzyon için görünür hız sabitini, $k_{r}$ yüzey kimyasal reaksiyonu için görünür hız sabitini, $k_{d}$ ürün veya kül tabakasından difüzyon için görünür hız sabitini ve $t$ reaksiyon süresini temsil etmektedir. Deneysel olarak bulunan dönüşüm kesri değerleri kullanılarak Eşitlik 57'nin sol taraflarının $t$ zamanına karşı grafikleri çizildiğinde orijinden geçen düz doğrular hangi model için elde ediliyorsa reaksiyon hızını o basamak kontrol eder. Elde edilen deneysel verilere yukarıda sözü edilen modeller uygulandığ

$$
-\ln (1-x)=k \cdot t
$$

Eşitlik 8'de $x$ dönüşüm kesrini, $k$ reaksiyonun görünür hız sabitini ve $t$ reaksiyon süresini temsil etmektedir. Çözelti derişimi, katı/sıvı oranı, karıştırma hızı ve reaksiyon sıcaklıkları için Eşitlik 8'in sol tarafının t'ye karşı çizilen doğruların oluşmadığı gözlenmiştir. Katı akışkan reaksiyonların kinetiğini izah etmek için yukarıda verilmiş olan heterojen reaksiyon modellerinden başka homojen reaksiyon modelleri de kullanılarak deneysel veriler analiz edilebilmektedir. Elde edilen dönüşüm kesri verilerine homojen modeller uygulandığı zaman kalsine uleksitin amonyum sülfat çözeltilerinde çözünme kinetiğini ifade etmek için en uygun modelin, integre edilmiş hali Eşitlik 8'de verilen yalancı birinci mertebe kinetik model olduğu gözlenmiştir.

grafikleri Şekil 10-13'de gösterilmiştir. Bu şekillerden görüleceği gibi orijinden geçen düz doğrular elde edilmiştir. 


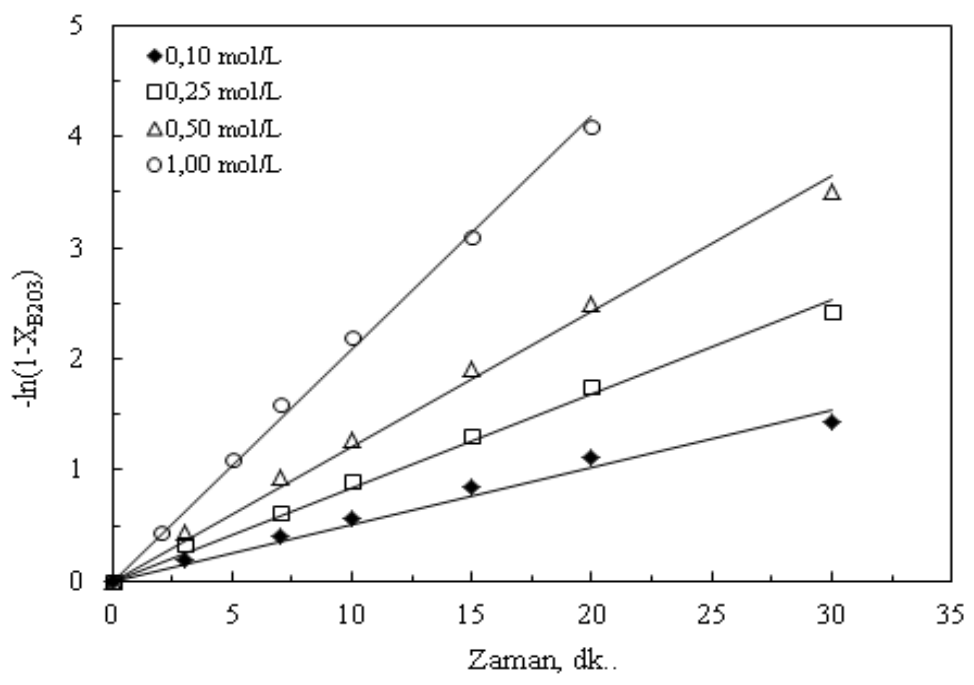

Şekil 10. Farklı derişimler için reaksiyon süresine karşı $-\ln \left(1-\mathrm{XB}_{2} \mathrm{O}_{3}\right)$ grafiği.

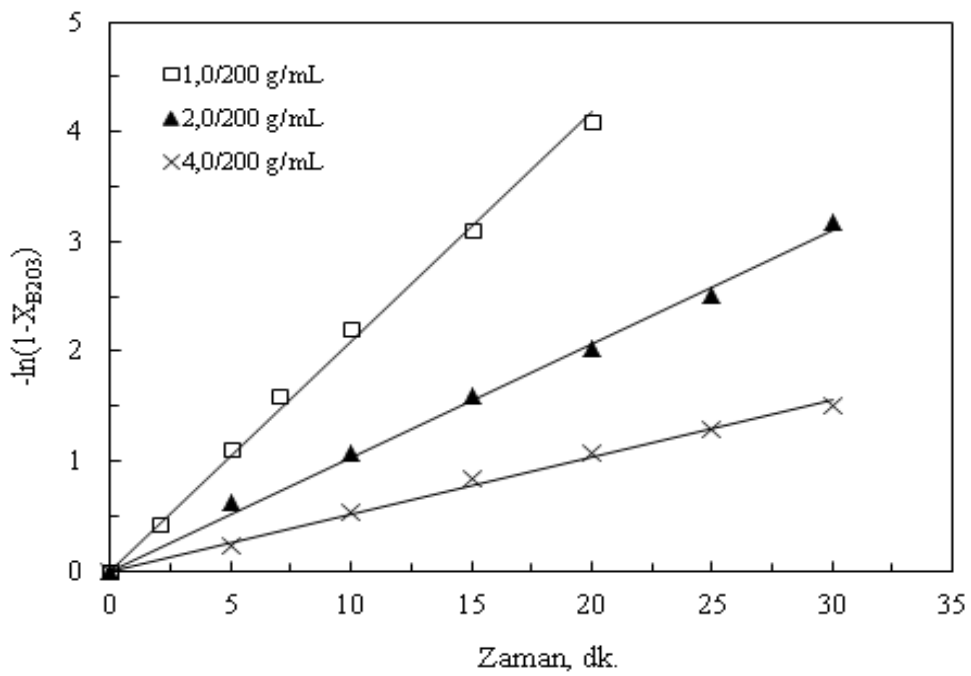

Şekil 11. Farklı kat1/sıvı oranları için reaksiyon süresine karşı $-\ln \left(1-\mathrm{XB}_{2} \mathrm{O}_{3}\right)$ grafiği.

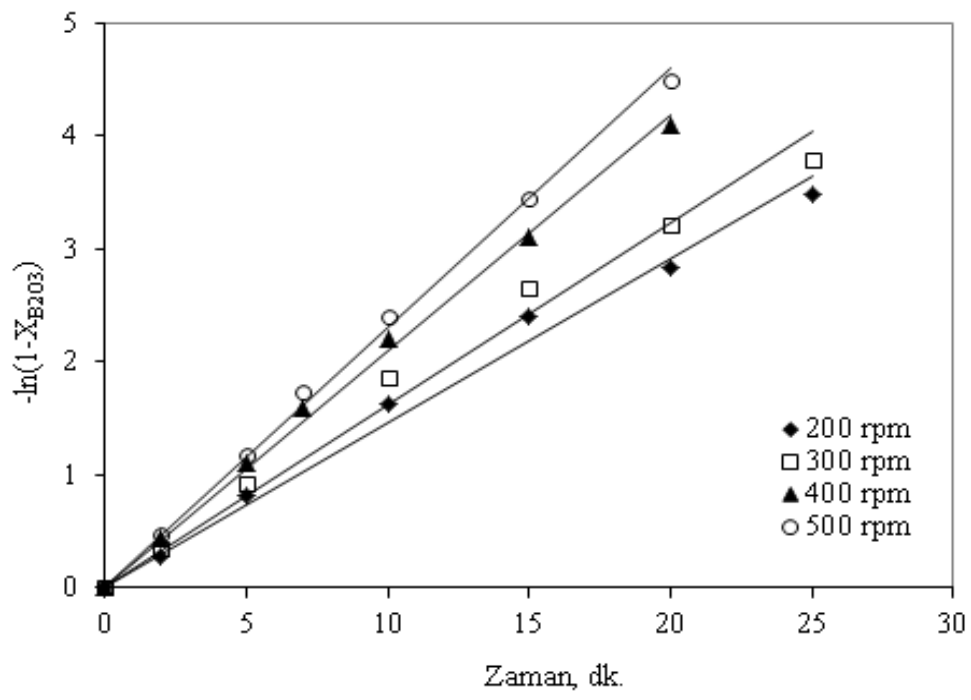


Şekil 12. Farklı karıştırma hızları için reaksiyon süresine karşı $-\ln \left(1-\mathrm{XB}_{2} \mathrm{O}_{3}\right)$ grafiği.

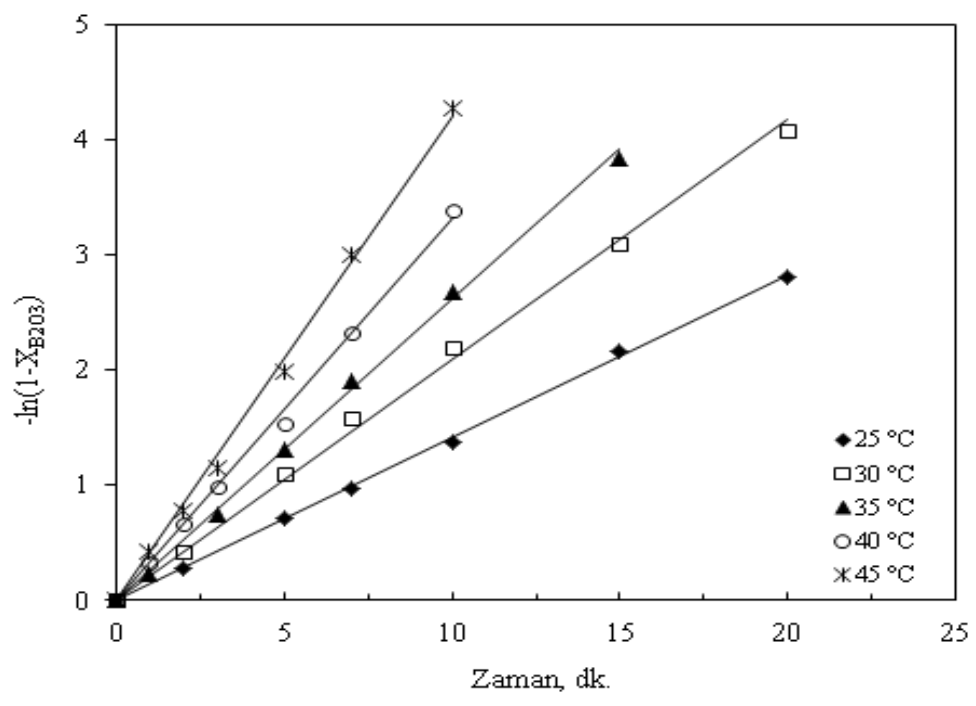

Şekil 13. Farklı sıcaklıklar için reaksiyon süresine karşı $-\ln \left(1-\mathrm{XB}_{2} \mathrm{O}_{3}\right)$ grafiği.

Reaksiyon hız sabitinin ( $k$ ) deney parametrelerine bağlılığı Eşitlik 9'daki gibi yazılabilir.

$$
k=k_{0} \cdot(C)^{a} \cdot(K / S)^{b} \cdot(K H)^{c} \cdot \exp \left(-\frac{E_{a}}{R T}\right) \cdot t
$$

$\mathrm{Bu}$ eşitlikte $k_{0}$, Arrhenius sabitini (1/s); C, çözelti derişimini $(\mathrm{mol} / \mathrm{L}) ; \mathrm{K} / \mathrm{S}$, kat1/sıv1 oranını $(\mathrm{g} / \mathrm{mL}) ; \mathrm{KH}$, karıştırma hızını $(r p m) ; E_{a}$, aktivasyon enerjisini $(\mathrm{J} / \mathrm{mol})$; $\mathrm{R}$, ideal gaz sabitini $(\mathrm{J} / \mathrm{mol} . \mathrm{K})$; T, sicaklığ $1(K)$ temsil etmektedir. $a, b$ ve $c$ sabitleri reaksiyon hızının ilgili parametreye olan bağlılığını ifade etmektedir. Şekil 10, 11 ve 12'deki doğruların eğimleri sırasıyla çözelti derişimi, katı/sıvı oranı ve karıştırma hızı için görünür hız sabiti değerlerini verir ve $a, b$ ve $c$ üslerinin hesaplanmasında kullanılır. Yapılan hesaplamalar sonucunda $a, b$ ve $c$ üslerinin değerleri sırasıyla $0.55,-0.89$ ve 0.50 olarak belirlenmiştir.

Çözünme prosesinin aktivasyon enerjisini hesaplamak için Şekil 13'teki düz doğruların eğimlerinden görünür hız sabitleri belirlenmiş ve Şekil 14'de verilmiş olan Arrhenius grafiği oluşturulmuştur. Şekil 14'deki doğrunun eğiminden de mevcut çözünme prosesi için aktivasyon enerjisi $42 \mathrm{~kJ} / \mathrm{mol}$ olarak hesaplanmıştır. Doğrunun kaymasından Arrhenius sabiti $4.16 \times 10^{4}$ (1/s) olarak belirlenmiştir.

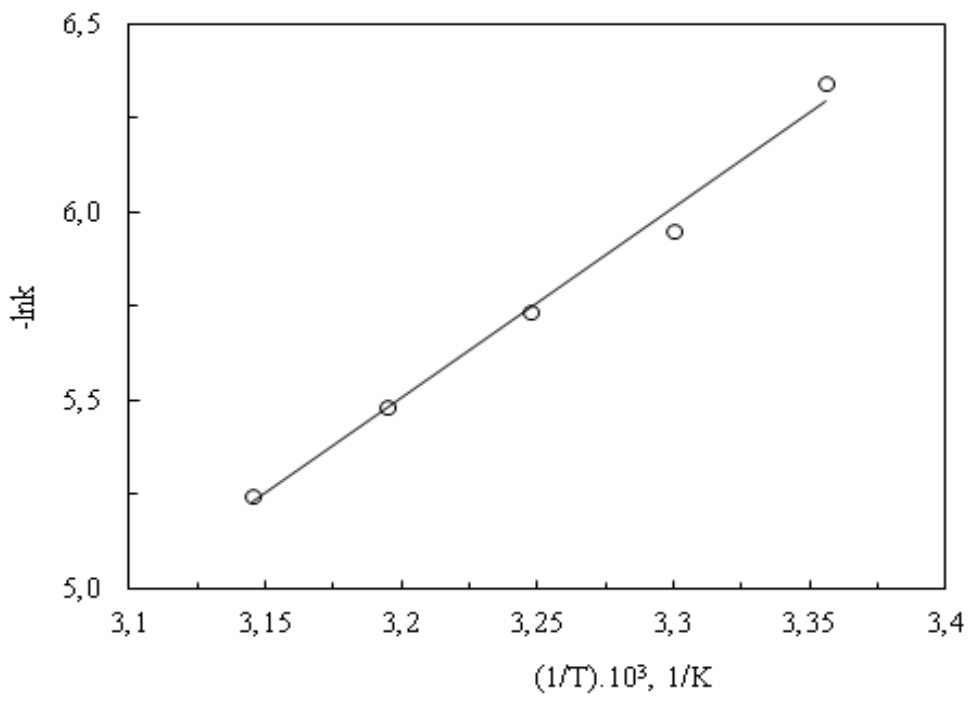

Şekil 14. Çözünme prosesi için Arrhenius grafiğgi. 
Sonuç olarak, kalsine uleksitin amonyum sülfat çözeltilerindeki çözünme kinetiğini temsil etmek üzere Eşitlik 10'da verilmiş olan ifade yazılabilir.

$$
-\ln \left(1-X_{B_{2} O_{3}}\right)=4.16 \times 10^{4}(C)^{0,55}(K / S)^{-0,89}(K H)^{0.50} \exp \left(\frac{5045}{T}\right) t
$$

\section{SONUÇLAR}

$\mathrm{Bu}$ çalışmada uleksit mineralinin amonyum sülfat çözeltilerinde çözünmesi üzerine kalsinasyon işleminin etkisi araştırılmıştır. Farklı sıcaklıklarda kalsine edilmiş uleksit minerali kullanılarak yapılan deneyler sonucunda, kalsinasyon prosesinin uleksitin çözünme hızı üzerinde önemli bir etkisinin olduğu belirlenmiştir. $150{ }^{\circ} \mathrm{C}$ 'ye kadar kalsine edilmiş uleksit örneklerinin çözünme hızında artış olduğu görülmüştür. $\mathrm{Bu}$ sicaklıktan daha yüksek sıcaklıklarda kalsine edilmiş örneklerle yapılan deneylerde ise çözünme hızında bir azalma olduğu tespit edilmiştir. En yüksek çözünme değerlerinin elde edildiği kalsine örnekler kullanılarak çözelti derişimi, katı/sıv1 oranı, karıştırma hızı ve reaksiyon sıcaklığının çözünme hızı üzerindeki etkileri incelenmiştir. Çözelti derişimi ve reaksiyon sıcaklığın artması, katı/sıv1 oranının ise azalmasıyla çözünme hızının arttığı bulunmuştur. Çözünme kinetiğinin yalancı birinci mertebe kinetiğe uyduğu belirlenmiş ve çözünme prosesi için aktivasyon enerjisi $42 \mathrm{~kJ} / \mathrm{mol}$ olarak hesaplanmıştır.

\section{KAYNAKLAR}

[1] Ü. İpekoğlu, and M. Polat, "Bor endüstrisine genel bakış”, Madencilik, vol. 26, pp. 5-16, 1987.

[2] M. S. Celik, H. A. Uzunoglu, and F. Arslan, "Decrepitation properties of some boron minerals", Powder Technology, vol. 79, pp. 167-172, 1994.

[3] M. Tunç, H. Erşahan, S. Yapici, and S. Çolak, "Dehydration kinetics of ulexite from thermogravimetric data", Journal of Thermal Analysis and Calorimetry, vol. 48, pp. 403-411, 1997.

[4] S. Şener, G. Özbayoğlu, and Ş. Demirci, "Changes in the structure of ulexite on heating", Thermochimica Acta, vol. 362, pp. 107-112, 2000.

[5] L. Stoch, "On a model of thermal internal decomposition of solids”, Thermochimica Acta, vol. 203, pp. 259-267, 1992.

[6] H. Erşahan, M. Tunç, A. Ekmekyapar, and S. Yapıcı, "Flash dehydration of ulexite and investigation of dehydration kinetics from thermogravimetric data”, Thermochimica Acta, vol. 250, pp. 125-135, 1995.

[7] Y. Erdoğan, A. Zeybek, A. Şahin, and A. Demirbaş, "Dehydration kinetics of howlite, ulexite, and tunellite using thermogravimetric data”, Thermochimica Acta, vol. 326, pp. 99-103, 1999.

[8] S. Şener, and G. Özbayoğlu, "Investigation of structural chemistry of thermal processes applied for improvement of grindability of ulexite”, Physicochemical Problems of Mineral Processing, vol. 34, pp. 25-33, 2000.

[9] A. Künkül, S. Yapıcı, M. M. Kocakerim, and M. Çopur, "Dissolution of thermally dehydrated ulexite in sulfuric acid solution”, Industrial and Engineering Chemistry Research, vol. 36, pp. 4847-4851, 1997.

[10] G. Tekin, Y. Onganer, and M. Alkan, "Dissolution kinetics of ulexite in ammonium chloride solution”, Canadian Metallurgical Quarterly, vol. 37, pp. 91-97, 1998.

[11] M. Alkan, C. Çifçi, F. Ayaz, and M. Doğan, "Dissolution kinetics of ulexite in aqueous EDTA solutions”, Canadian Metallurgical Quarterly, vol. 39, pp. 433-440, 2000.

[12] M. Alkan, M. Doğan, and H. Namlı, "Dissolution kinetics and mechanism of ulexite in oxalic acid solutions”, Industrial and Engineering Chemistry Research, vol. 43, pp.1591-1598, 2004.

[13] A. Künkül, and N. Demirkıran, "Dissolution kinetics of calcined ulexite in ammonium carbonate solutions”, Korean Journal of Chemical Engineering, vol. 24, pp. 947-952, 2007.

[14] N. Demirkıran, "Leaching kinetics of calcined ulexite in ammonium nitrate solutions", Journal of Chemical Engineering of Japan, vol. 40, pp. 755-760, 2007.

[15] N. Demirkiran, N. Bayrakçı, and C. Asin, "Dissolution of thermally dehydrated ulexite in ammonium acetate solutions”, Transactions of Nonferrous Metals Society of China, vol. 23, pp. 1797-1803, 2013.

[16] A. Künkül, N. Demirkıran, and A. Baysar, "Dissolution kinetics of ulexite in ammonium sulfate solutions”, Industrial and Engineering Chemistry Research, vol. 42, pp. 982-986, 2003.

[17] H. Gülensoy, Kompleksometrinin Esasları ve Kompleksometrik Titrasyonlar, İstanbul: Fatih Yayınevi Matbaas1, 1984.

[18] C. Y. Wen, "Noncatalytic heterogeneous solidfluid reaction models", Industrial and Engineering Chemistry, vol. 60, pp. 34-54, 1968.

[19] O. Levenspiel, Chemical Reaction Engineering, New York: John Wiley, 1972. 